\title{
2
}

\section{Getting from Sunda to Sahul}

\author{
Jim Allen \\ Department of Archaeology, La Trobe University, Australia \\ jjallen8@bigpond.net.au \\ James F. O'Connell \\ Department of Anthropology, University of Utah, USA
}

\section{Introduction}

The level of intentionality in the behaviour of early modern humans is a continuing debate that we have had with Atholl over the years. For our part, we argue that the cognitive abilities of early modern humans, reflected in the patterns of the late Pleistocene archaeological records, are qualitatively different from their predecessors and not vastly different from our own. This being the case, we feel able to assume purpose in past human behaviour that Atholl does not. Presented with evidence that is often meagre, indirect or ambiguous, Atholl counters with explanations that require little or no intent on the part of these humans. Nowhere has our debate crystallised as clearly as in the case of early watercraft and their use in colonising Sahul, a milestone modernhuman achievement for which no direct evidence is or is likely to become available. We all accept without question that it happened, that watercraft were involved and that this water crossing was only achieved by modern humans. Despite some continuing debate, it is increasingly likely that first colonisation occurred about 45,000 years ago. Beyond this, we do not know where people stepped off the Asian continent, what routes to Sahul may have been taken, what length of time elapsed between humans leaving Sunda and arriving in Sahul (Figure 1), what viable population sizes might have been needed to form successful colonisations, where first Sahul landfall was, whether the first successful entry was preceded by unsuccessful ones, whether there were multiple successful entries at different locations, and so on. But one can engage in constructive, theoretically driven, potentially testable speculation on all of these points.

This paper was first presented at an ANU seminar in 2005 to draw attention to these questions, largely untouched since Birdsell's (1977) seminal paper. It provoked useful discussion between Atholl and us and was a focus for subsequent work (Bulbeck 2007; O'Connell et al. 2007; O'Connor 2007), and we offer it here to acknowledge our intellectual debt to Atholl Anderson.

Since direct evidence to answer questions concerning the initial colonisation of Sahul is 


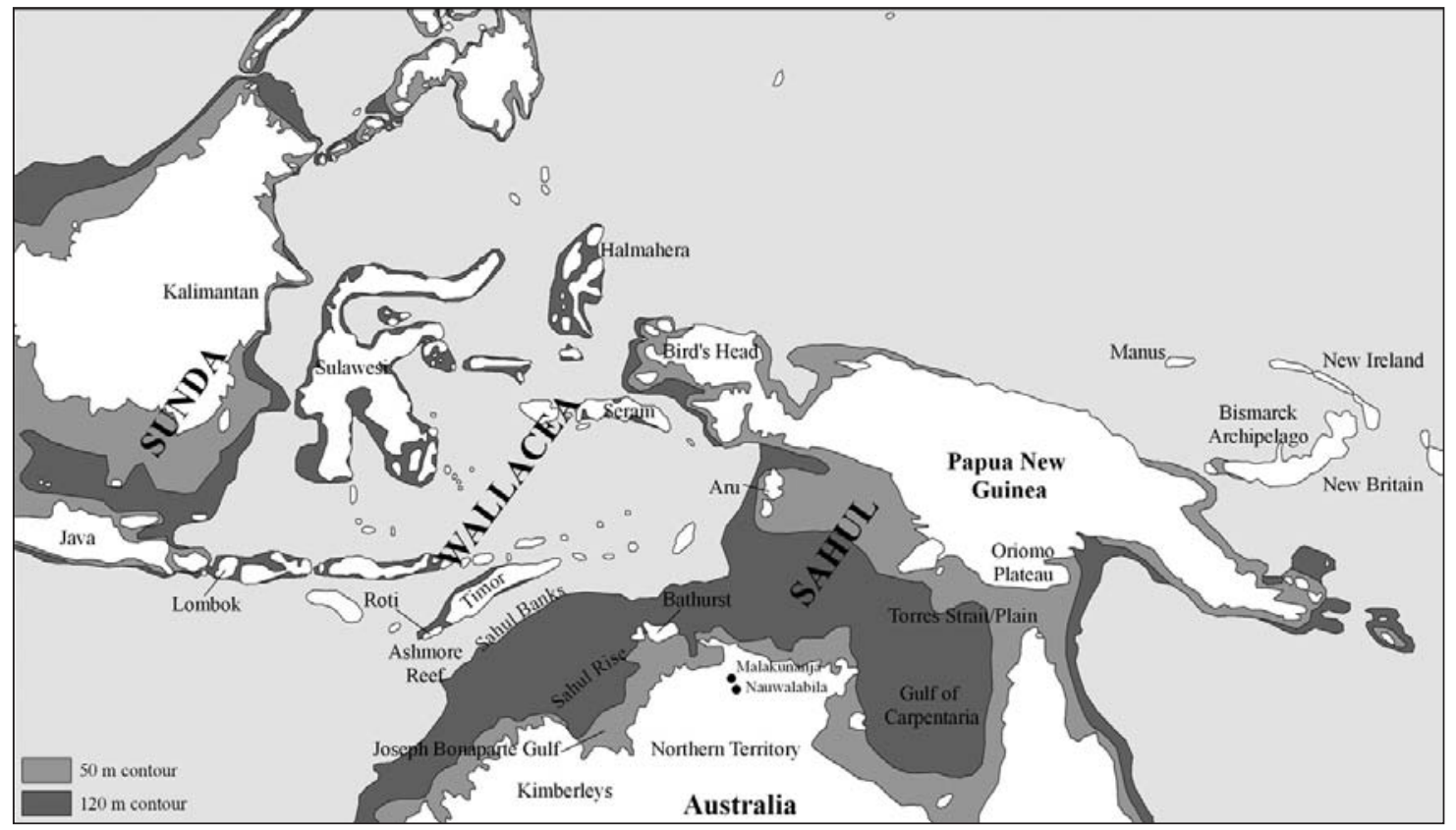

Figure 1. Map of Wallacea showing places referred to in the text.

unlikely to be forthcoming in the archaeological record, alternative approaches are limited. For us, inductive approaches are currently unsatisfactory, relying as they do on arguable interpretations of sketchy data that are frequently date-driven. For example, O'Connor (2007) predicates her entire argument on a human arrival date in Sahul of 60,000 BP. This date, mooted 18 years ago (Roberts et al. 1990), has received no compelling support in the intervening years and today only a tiny minority defend it. The incorrect argument of Chappell et al. (1996) and Fifield et al. (2001) that our appeals to a younger chronology were the result of blind adherence to radiocarbon has been continuously weakened by the increasing use of luminescence and improved radiocarbon pre-treatment (ABOX-SC). To date, neither technique has produced an archaeologically associated date approaching 50,000 BP, outside the two original Northern Territory claims of Nauwalabila and Malakunanja. Regardless of what calibration is applied to available radiocarbon dates, a current 'best-estimate' date for human arrival is c. 45,000 years ago, or a little earlier (Allen and O'Connell 2003; O'Connell and Allen 2004; O'Connell et al. 2007).

A better alternative is to develop models for this colonisation that will throw up testable hypotheses to approach these questions. This paper offers one such model that assumes that the first successful human colonisation of Sahul was the consequence of many small but deliberate decisions that involved conscious and continuing risk assessment of behaviours intended to maximise reproductive fitness. People crossed from Sunda to Sahul as a consequence of these behaviours, rather than with conscious intent, like the chicken, to get to the other side. Even so, the colonisation of Sahul was not accidental.

\section{Background}

The first public recognition that human entry into Australia and New Guinea at any time in the past required the crossing of a significant water barrier might be attributed to Grafton Elliot Smith at the meeting of the British Association for the Advancement of Science in Sydney in 1914 (Elkin 1978:99). Although a glacio-eustatic explanation of relative sea-level changes had first appeared in 1842, and occasionally later in the 19th century, it was not until 1910 that 
a paper by R.A. Daly revived the theory and finally dismissed previously accepted models of sunken land bridges and lost continents (Daly 1910; Baulig 1935).

Today, we take for granted that this water barrier, with all routes having at least one crossing of about $90 \mathrm{~km}$ whatever the sea level, has always confronted humans moving into Sahul. It is this barrier that kept Homo erectus west of Timor and Sulawesi for more than a million years, and it is the ability to overcome this barrier that has been and continues to be a principal hallmark of the behavioural modernity of the initial human colonists into Sahul.

So commonplace is this understanding that with a few exceptions, most notably Joseph Birdsell in 1977, no close attention has been paid to how or where the initial crossing may have been achieved. A route from Timor to northwest Australia has sometimes been favoured (e.g. Butlin 1993), although on arguable evidence. Indeed, recently both Australianists (e.g. Chappell 2000; O'Connor and Chappell 2003) and European scholars (e.g. Foley and Lahr 1997) have posited distinctly separate colonisations of Australia and New Guinea even though these countries comprised a single landmass at the time of colonisation, regardless of which chronology is favoured for that event. Instead, models of Australian colonisation have mostly discussed how people spread through the continent after they landed (e.g. Bowdler 1977; Horton 1981; Rindos and Webb 1992).

However, the question of how landfall was made is fundamental in considering how Australia and New Guinea might subsequently have been settled, because understanding the processes of successfully establishing a foothold in Sahul directly informs the strategies that eventually took people to Tasmania and into the nearer western Pacific islands.

Past studies have called up a diverse range of questions, from the motivation(s) of first colonists and the nature of watercraft involved, to the relative inputs of biology, culture and adaptability, speed of settlement and technological inventiveness. We take as a useful starting point Joseph Birdsell's 1977 paper 'The recalibration of a paradigm for the first peopling of Greater Australia'.

\section{The Birdsell model}

Birdsell's larger model was primarily biological in nature and paid scant attention to culture as a contributing factor. In large part, it was concerned with population events after arrival in Australia, whether people remained coastally oriented or moved inland, the time needed to infill the continent, and so on.

However, Birdsell's enduring contribution to modelling Sahul colonisation concerned his detailed treatment of probable routes for watercraft between the Sunda and Sahul continental shelves. Like many before and since, Birdsell favoured minimalist assumptions and sought to define those routes that provided the fewest, safest and shortest sea crossings. He isolated three pertinent variables concerning each target island, the next island to be reached from home base. These were distance to the target island, target height (and thus visibility from the home island) and target width, the notion being that wider targets could be more readily reached with limited navigation and other sailing capabilities. These three variables taken together were seen to indicate preferred options, apart from distance alone. A high and wide target, for example, could offset a longer distance.

Birdsell defined three variants for a northern route through Sulawesi and two variants for a southern route through Timor. The two northernmost routes arrived in present-day New Guinea in the vicinity of the Bird's Head; two middle routes arrived, depending on sea level, at Aru and further south on the Torres Plain; while the southernmost route via Timor reached Sahul west of the present-day Kimberley region. These routes variously took from eight to 18 
stages and each involved from one to four stages of more than $30 \mathrm{~km}$. From north to south, the longest crossings of the five routes, based on a sea level of $-150 \mathrm{~m}$, were, respectively, $93 \mathrm{~km}, 69$ $\mathrm{km}, 103 \mathrm{~km}, 98 \mathrm{~km}$ and $87 \mathrm{~km}$.

Birdsell explored a mid-range scenario by raising the sea level to $-50 \mathrm{~m}$. At this level, all routes increased some inter-island distances, but such a sea-level change had little real effect on the three northern routes, apart from the problem of reaching Sulawesi in the first place, where, by Birdsell's reckoning, the gap doubles to $87 \mathrm{~km}$. Mulvaney and Kamminga (1999:108) indicated that Birdsell favoured the southern route through Timor, but this was the case only when the sea was at its lowest point. Birdsell (1977:130) noted that during periods of higher sea level, the Timor route would have been 'excessively formidable' and 'of no great importance'. Birdsell believed there was 'a constant if somewhat straggling trickle of small groups of human beings over all or most of the routes' and given the limitations of potential watercraft, group sizes were likely to have consisted of small families. He also accepted that these were staged journeys, arguing that when each new target island was reached, there would be a long period of adaptation to local wind, water and tides, and that the crossing from Sunda to Sahul may have taken centuries (1977:147).

Some authors have rejected this view. For example, Thiel (1987:238-239) reckoned that by drifting on the longest possible route from Sunda to Sahul, people could have made the crossing in 14 days. In our view, such speculations are obfuscating, since such a journey does not conform to the normal known behaviour of hunter-gatherers, ignores the geographic and ecological potentials of Wallacea, and makes unwarranted assumptions about weather, freshwater requirements and long-term biological viability, just to name a few. At any given time, a bird in the hand on Sulawesi may well have been worth two potential birds in the Kimberleys.

\section{On routes}

Many commentators after Birdsell have preferred the shortest routes and assumed minimalist conditions such as the most basic watercraft and smallest biologically viable colonist group size. As well, most have assumed a continuous west-to-east movement, with few westward returns, except where water gaps were short. Birdsell's colonising routes covered most available options, and these routes have been reproduced mostly uncritically by subsequent commentators.

One exception is Butlin (1993:16-25), who determined that the Timor to Kimberley route offered the best chance of success and was probably the route most regularly used. Butlin also based his judgement on minimalist assumptions, pointing out that Timor was more easily reached during the Pleistocene than was Borneo/Sulawesi (his assumed point of departure to reach New Guinea) and that the Kimberley route required less navigational skill because Australia had huge target width compared with the target islands of Wallacea.

Butlin used newer data, unavailable to Birdsell, and noted that if the sea level fell to $60 \mathrm{~m}$ below present levels (and in many cases a lesser amount of $-30 \mathrm{~m}$ to $-40 \mathrm{~m}$ ), a long chain of shoal islands, running roughly parallel to Timor and Roti, would appear on the eastern side of the Timor Trough. These are now known as the Sahul Banks (Figure 1). If viable, these islands would reduce the single crossing to the Australian shore considerably. Butlin estimated some of these islands might be as close as $90 \mathrm{~km}$ from Timor/Roti and he believed they would be visible from Timor. East of these islands, the Sahul Rise is a low formation of limestone outcrops cut by tidal channels that were exposed by sea levels between $-60 \mathrm{~m}$ and $-80 \mathrm{~m}$ (Figure 1). Butlin saw these as stepping stones that would have led in the north on to Bathurst Island and in the south on to the southern side of Joseph Bonaparte Gulf. 
To bolster his case, Butlin (1993:33-41) offered an additional series of 'pull' and 'push' factors. For Timor-Australia, pull factors included smoke, bushfire glow and migratory birds, and more generally for Island Southeast Asia, inter-island visibility. Push factors were more strictly Malthusian, centred on population increase and consequent reductions in resource availability.

\section{A modelling approach}

In contrast to this inductivism, we believe there are alternative ways to look at the question of how Sahul was settled, by developing theoretical models that may refocus arguments about sea levels, marine technological capabilities, motivations to move, and the like. Ideally, these should be testable in the data (available or potentially gatherable), or minimally make sensible appeal to uniformitarian principles of human behaviour, well beyond notions like exploration being a fundamental component of the human spirit. We also take the view here that there is no imperative to assume minimalist conditions a priori. Regardless of whether the behaviourally modern-human move eastwards began in Africa or Southwest Asia or even Southeast Asia, it is reasonable to assume that the adaptive ability that carried modern humans through and beyond the previous range of Homo erectus was capable of sufficient invention to reach Sahul as a part of a process involving conscious assessment of the risks and the minimisation of those risks, rather than as an accident.

\section{The question of sea levels}

Contrary to the minimalist views of many commentators who have favoured lower sea-level periods for the initial colonisation of Sahul on the grounds of shorter distances, Thiel (1987) proposed that this colonisation was the result of rising seas reducing land area and drowning islands, with the resulting pressures leading to human migration. The central tenet of this argument had been shown already to be probably wrong, when Dunn and Dunn (1977) demonstrated that rising sea levels significantly increased the length of coastline in Sundaland, thus catering for higher populations in this important ecotone (see also Bellwood 1990). However, Thiel may have been right for the wrong reasons. Chappell (1993:45-47; 2000:89-90) has argued that the earliest voyages to Sahul probably occurred during phases of sea-level rise or during relative maximum levels because rising seas favour the development of coral reefs and lagoons; rivers and streams develop estuaries and mangroves and trap sediments that can move landwards, contributing to backwater swamp and inland waterway expansion and the formation of deltaic plains. Such sedimentary 'aquatic coastal environments' favour the regular use of watercraft, as opposed to the rocky coastal environments associated with falling and low sea levels, especially on precipitous coasts. Under these conditions, corals form only a narrow fringing reef and lagoons become dry land. Rivers are entrenched in narrow valleys and discharge their sediment directly into the ocean; coastlines are likely to be steep and simple with few offshore islands. Areas of sedimentary coast 'would have been small and uncommon on the islands from Lombok to Timor, the Moluccas, much of northern New Guinea and the Bismarks' during falling-sea periods (Chappell 2000:90).

If, as Chappell suggests, watercraft usage fluctuated with sea-level rises, it would seem likely Sahul was reached first during a high sea-level/high-usage phase. Chappell (1993:45) notes that for levels between $-20 \mathrm{~m}$ and $-75 \mathrm{~m}$, inter-island distances do not vary very much, with three exceptions, Kalimantan to Sulawesi, Tanimbar to the Aru shelf, and especially Timor to the Kimberley. At -75 m, Butlin's stepping-stone islands are 'small and sparse', and they disappear at $-30 \mathrm{~m}$. The Timor route is the most problematic in terms of distances at all lowerings less than 
$-75 \mathrm{~m}$. Distances between target islands during the time of probable landfall (even allowing this to be as wide a margin as 60 kya years to $40 \mathrm{kya}$ ) were most favourable along the northern route from Sulawesi to New Guinea.

The Lambeck and Chappell (2001) sea-level curve constructed from Huon Peninsula (Papua New Guinea) data indicates there were four occasions during the 60-40 kya period when the sea levels rose and peaked, before falling again (Figure 2). These oscillations ranged between c. -80 $\mathrm{m}$ and $-42 \mathrm{~m}$, with the four maxima varying between $-53 \mathrm{~m}$ and $-42 \mathrm{~m}$. While we favour the last of these high stands, at c. $44 \mathrm{kya}$, as a probable arrival time, for reasons argued elsewhere (Allen and O'Connell 2003; O'Connell and Allen 2004), the model put forward here holds for any of these options, given that the high-stand maxima vary by only c. $11 \mathrm{~m}$.

Working from maps published by Voris (2000), there are few differences in land exposed by the $-40 \mathrm{~m}$ and $-50 \mathrm{~m}$ contours. In both cases, the Gulf of Carpentaria is open to the sea and the Aru Islands are part of the mainland. But at $-75 \mathrm{~m}$, the Torres Plain is greatly extended and the gulf has become Lake Carpentaria. At intermediate times, fluctuating salinities suggest this was a complex estuarine embayment (Torgersen et al. 1985).

This leads to three other questions concerning lowered sea levels. Somewhat contrary to his own argument, Butlin (1993:24) notes that the islands of the Sahul Banks rose out of a part of the ocean frequently more than $150 \mathrm{~m}$ in depth. With sea levels at c. $-40 \mathrm{~m}$ these islands were probably small atolls, but at lower sea levels they would have presented sheer coral cliffs with heights proportional to sea level fall below $-40 \mathrm{~m}$, thus suggesting their usefulness as stepping stones during periods of very low sea level would be minimal. In the Pacific, similar islands are known as makatea islands, formed there by tectonic uplift at plate margins. Many lack surface water, with rainwater disappearing into the karst. Whether the Sahul Banks comprised makatea islands or coral atolls is unclear but of little consequence; both are precarious for settlement (Kirch 2002:49-50).

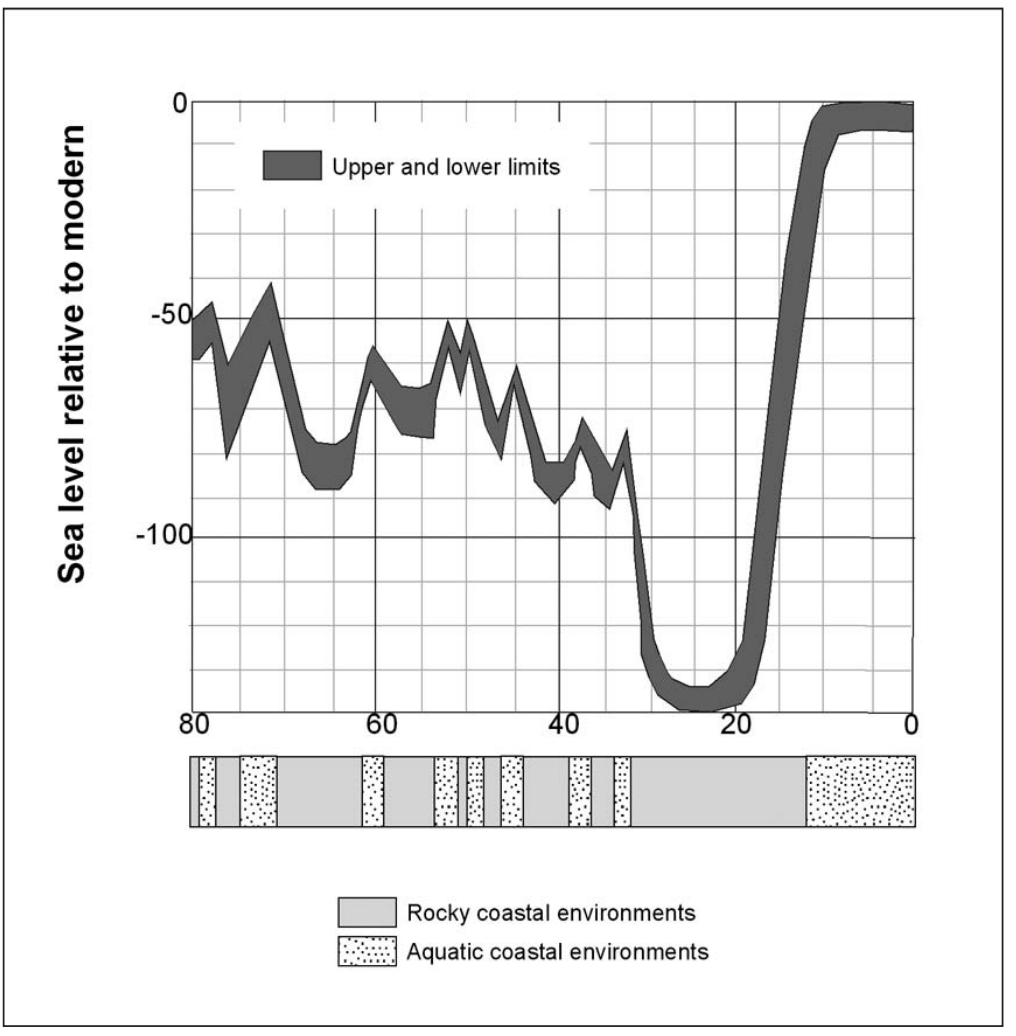

Figure 2. Pleistocene sea-level fluctuations following Lambeck and Chappell (2001). Data for periods of rocky versus estuarine coasts from Chappell (2000). 
The second question follows directly. What might have been the propensity of such islands to provide food and especially fresh water in any quantity? Birds, birds' eggs and marine foods would support seafarers in transit, but might not assist any longer-term settlement. Fresh water may have been more difficult to obtain, even in the short term. The Ashmore Reef, about 100 $\mathrm{km}$ south of Roti, consists of three small vegetated islands on a large area of reef. Currently, fresh water is available from wells that tap into fresh-water lenses (the Ghyben-Herzberg aquifer) beneath the surface of the islands. The sizes and salinity distributions of such acquifers are dependent on many factors, including rainfall, the amount and nature of surface vegetation, the nature and distribution of soils and the size of an island, particularly the width from sea to lagoon. It is thus uncertain that such low islands anywhere in Wallacea would have greatly assisted movements towards Sahul, apart from providing fishing and birding grounds.

The third question concerns the viability of different coasts for hunter-gatherer settlers beyond the general parameters outlined by Chappell, who himself noted exceptions to them (Chappell 1993:46). Remnant 'aquatic' coastal environments may have supported some human movement at periods of lower sea level. Demonstrating this possibility seems to require better data than are currently available. In particular, it is reasonable to ask whether the greatly expanded Sahul plain west of the Kimberley Plateau would have had a sufficient number of streams and rivers to facilitate successful settlement by chance arrivals, especially in periods when lower sea levels were accompanied by lower precipitation.

\section{Watercraft and seafaring}

Almost all commentators have assumed a minimalist position when speculating about what marine technology was employed in the successful colonisation of Sahul. While such a position makes the fewest assumptions, it should not deny the possibility that greater technological inventiveness was involved, given that such inventiveness is one hallmark of modern humans (O'Connell and Allen 2007) and that the speed with which distant parts of Australia were colonised strongly suggests initial colonisation was inventive and systematic. Added to this, we now recognise that watercraft had to be of sufficient size or number to get founding populations into Sahul (see also Irwin 1992:27). The sizes and compositions of such populations are considered in more detail below.

Anderson (2002:13-19) has most recently summarised the minimalist case. Along with many commentators, he favours bamboo rafts for their buoyancy, speed and ease of construction, and light displacement which would allow such a craft to be propelled by wind, even without sails. If bamboo rafts were used, however, there are interesting implications, for Birdsell (1977:144, following Munro 1868) argued that while suitable bamboos are nearly continuous along the northern route, they do not occur along the southern route beyond Java, and that if the southern route was used, different materials would have been demanded. Although the Pleistocene distribution of bamboo is unknown, if drier and cooler conditions pertained we might expect its Pleistocene distribution to have been even narrower than today. Understanding distributions of bamboo 45,000 years ago is also complicated by the likelihood that its usefulness to humans caused them to move this plant to locations beyond its natural distribution at that time.

Anderson also considers initial settlement required no more than occasional drift voyaging and he suggests systematic voyaging in Pleistocene Near Oceania remains improbable. Whether he includes coastal voyaging in this dismissal is unclear. But while people reached Manus by at least 20,000 years ago, involving a crossing of at least $180 \mathrm{~km}$ including some $60 \mathrm{~km}$ out of the sight of land, Anderson argues this could have been achieved by a drifting or paddled raft.

Anderson (2000:16-17) is critical of both the term and the concept of Irwin's proposed 
'voyaging nursery', extending from Island Southeast Asia to the Bismarcks. Regardless, we continue to find utility in Irwin's data and arguments, particularly as they pertain to Wallacea. Whether or not earlier watercraft were in use still further west is unimportant here; it is no leap of faith to suppose that once the larger landforms of the Sunda shelf had been left behind, the technological sophistication and use of watercraft, even bamboo rafts, increased among the large and small islands of Wallacea.

Irwin (1992:18-30) initially followed Birdsell in examining questions of distance, angle of target and intervisibility, adding data and comment on climate and weather, watercraft and navigation, passages in the voyaging corridor, and voyaging intent and frequency. He observed that even with sea levels at $-40 \mathrm{~m}$ to $-70 \mathrm{~m}$, distances between high islands - those islands visible at a distance - were much the same when sea levels were lowest, so that the distances and angles he calculated were similar to Birdsell's.

By translating island heights into the specific distances that land might be ahead, Irwin demonstrated that Birdsell's northern route through Halmahera provides unbroken intervisibility; his two other northern routes are on the borders of intervisibility; but the two southern routes, through Tanimbar and to the Kimberley coast, are both blind. Again, this intervisibility remains essentially constant, whatever the sea level. Moving westwards from New Guinea in the reverse direction (an important consideration, see below), the Halmahera route is just beyond the limits of intervisibility, but the route through Seram has continuous intervisibility, which it did not have moving eastwards (Irwin 1992:21-22).

Given the equatorial position of Wallacea, Irwin (1992:24-25) argues that there would have been no wholesale latitudinal displacement of weather patterns during the period of interest. As is the case today, the southern winters would have been dominated by the southeasterly trade winds and the summers by the northwest monsoon winds. Currents followed the wind patterns, such that seasonal reversals of winds and currents would have been predictable. In particular, their equatorial position would have placed both the voyaging corridor and the settled islands between northern and southern tropical-cyclone belts. While elsewhere sailors may avoid adverse cyclonic weather, frequently their settlements do not. This seems likely to have been a further advantage of the corridor for first settlers.

Thus, seasonal two-way sea journeys would have been facilitated by winds and currents. The most likely exception is again the Timor-Kimberley coast route. A computer simulation by Wild (1985:69, cited in Irwin 1992:28) found that most watercraft drifting from Timor during the monsoon season reached the Australian coast, but the reverse voyage was difficult, even during the southeasterly trades, when most craft were blown back on to the Australian coast or south into the Indian Ocean.

\section{Ideal free distribution (IFD) and optimal foraging theory}

Questioning whether the human settlement of Sahul was deliberate or accidental may be missing the point altogether. If a group leaves familiar territory, food-procurement success will decline and the probability of failure due to unpredictable events will increase (Wobst 1974:152-153). Long-distance moves will lower the population density and increase instability in social networks. Thus, large-scale or long-distance migrations are improbable; in Wobst's view 'colonisation would take place gradually and randomly by small breakaway groups along the fringes of the settled area'. In modelling the colonisation of the New World by 25 people, Wobst calculated a maximum migration speed would be only $5 \mathrm{~km} /$ year, a speed that could not be conceptualised as a conscious process of migration. 
We agree with this general position. Even so, reaching Sahul was only a matter of time once humans first moved beyond the Sunda mainland.

Watercraft were essential to move east from Sundaland, and whether or not watercraft sufficient to the task had been invented before or after the edges of the Sunda shelf had been reached is immaterial here. While it is currently impossible to calculate the costs and benefits for the first people of moving beyond this 'edge of the world', it is still a more effective way to consider the problem for hypothesis building than are appeals to the adventurous spirit. Humans do not take risks without some understanding of an eventual return that will justify such risks. We can assume reasonably that leaving the edge represented an increase in investment in marine technology, even if this technology was simple and unsophisticated. We can then only assume the benefits would fall into some of those categories that Butlin termed 'push' and 'pull' factors. Within the current argument, it is unimportant to specify these, be they crowding from population increase, declining returns from existing territories, or what Hiatt (2001) called colonisation by elopement.

What is important is to recognise that the investment in marine technology is a calculated response to some set of conditions that propels people into Wallacea. Once there, the probable imbalance between terrestrial and marine resources in relatively impoverished island habitats would demonstrate the possibility of increasing returns from marine resources as a function of improving technology, of which watercraft were a part. This is the way any distinctive materialcultural assemblages were developed in past cultural groups. In our view, the use of marine resources and increasing familiarity with them on the islands of Wallacea over time demanded a concomitant response in improved watercraft technology. This may still have been bamboo rafts. The notion does not demand canoes, outriggers, sails, or other more complex technology, but it does not deny them either.

In modelling the movements of behaviourally modern humans, we thus appeal to the ideal free distribution model (hereafter IFD). This was developed by Fretwell (1972) to account for distributions of dispersive birds in new habitats. It proposes that the way individuals occupy new territories is set up via habitat selection. Each habitat within a territory will have a different suitability, dependent on the number of occupants. The model suggests that in an empty landscape, the 'best' habitats, that is, those that optimise evolutionary success, will be occupied first.

But since optimality is density-dependent, there comes a point when optimal evolutionary success is threatened by population increase within the habitat. If habitat suitability declines with an increase in population density, then optimum distribution may become an unstable function of population size, where slight increases in population may cause major changes in distribution. When the suitabilty of the best habitat declines, as a function, for example, of increasing population depressing the availability of resources, and falls to the level of suitability of the next-most-suitable habitat, this second habitat will be occupied - and so on, in a cascading demographically driven pattern of habitat occupation where all occupied habitats have the same level of suitability, or in other words, all individuals have the same level of reproductive fitness. But this can occur only if all individuals are free to choose where they settle; that is, this is the pattern that settlement will ideally follow if no other constraints are applied.

The IFD model is not without its critics. Lima and Zollner (1996:132-133) point out that a dispersing animal will have little information about the distribution or number of living sites within a habitat or the greater landscape. They point out that IFD models mostly deal with small spatial scales that have high levels of available information and that opportunities for 
learning at large scales are minimal, since they involve the repeated abandonment and location of habitats that might be widely spaced, thus increasing risk. While such criticisms are valid, they might apply less to human groups that can disperse and regroup during exploration phases and exchange information via language, thus minimising risk.

While we perceive IFD as an overarching model that is useful in conceptualising how and why groups might occupy pristine territories, Fretwell was anxious to emphasise that the model only predicted the equalising of reproductive fitness if all individuals were free to occupy whatever territory they chose, and it is probable that in the face of finite resources at any particular location, those in possession moved to exclude other groups. At this more specific level, we model behaviour by appealing to optimal-foraging theory, a set of models for assessing food acquisition (Stephens and Krebs 1986; for a review of archaeological applications, see Bird and O'Connell 2006), a primary concern among hunter-gatherers and archaeologists reconstructing their past behaviour.

One of these models, the diet-breadth model, ranks available foods according to their potential to maximise nutritional-return rates, by assessing not only nutritional value, but also time spent in search, capture and processing. Marginal-value theory, on the other hand, determines the point in time when foragers should abandon one location for the greater benefits of another. As understood, this mostly means that higher foraging returns at the new location will compensate for lower present returns plus costs associated with moving. However, these costs may also include social costs, and at this point, we perceive how IFD and optimal-foraging models begin to meld.

Taken in conjunction, IFD and optimal-foraging theory provide us with a way to understand how Wallacea might have been crossed as part of a conscious foraging strategy that involved neither accidental castaways, nor deliberate colonisations. Under the diet-breadth model, technologies that reduce search and capture time and expand the list of available foods will be favoured. Thus, we would expect watercraft and fishing technologies to improve once people moved into the island world of Wallacea. We have expanded on these ideas elsewhere (O’Connell et al. 2007).

How might this operate on the ground? Let us assume that a behaviourally modern huntergatherer group exploits a territory that borders the Sunda shelf coast, the same barrier that has restricted earlier humans for more than a million years. Like these earlier humans, members of the group know islands exist to their east because they can see them from sea level; but unlike these earlier humans, they have (or develop) sufficient technology to occasionally reach these islands, utilise new sets of resources and return to their group. Even if the natural resources of the new location rival those in the existing group territory, this does not of itself make it a preferred habitat. Provided the suitability of the existing territory does not diminish, the social advantages of the established population there, from territorial knowledge to cultural association, from security from predators to marriage partners, maintains the original territory as the preferred location of the group.

Under Fretwell's IFD model, this balance is ultimately upset by population increase. However, the upset might equally be caused by diminishing resources in the territory, competition with neighbouring groups, or even short-term climate change such that the suitability of the habitat diminishes. While internal group conflict might cause fission, the decision to establish a new settlement on a peripheral island need not involve expulsion, nor indeed any conscious decision to go. A family or two may merely spend longer and longer periods away from their original group territory and in the new one; others might gradually join them until a new foraging territory comes into existence. The assumption here is that the initial group will settle in the 
habitat where diet breadth maximises its reproductive fitness (Beaton 1991). While the group remains small, all people joining it will settle in the same place because suitability is highest there. Since humans are gregarious, the variation to IFD known as Allee's principle will apply (Fretwell 1972:90-91). Initially, the suitability of the new habitat increases with an increase in the density of human groups, for the cooperative and social advantages already outlined. If at the same time the suitability in the original territory continues to decrease, it becomes advantageous to move into the new territory, until the suitability of the new territory approximates that in the former territory. Although the new territory will be different in its resources and their deployment, and human densities will differ in each, the IFD model suggests the reproductive fitness of both groups will equalise. As discussed in the next section, it may be necessary for the new group to maintain social and economic ties with its ancestral group for the exchange of different resources (a mutual benefit) and the exchange of genes (perhaps mainly a benefit to the new group).

The important point is that under the model, a small change in conditions, be it population increase, competitive increase, or resource downturn, can occasion a relatively large change in the distribution of the humans involved.

Some islands, such as Suluwesi, are large and would likely contain multiple territories, while smaller islands might be bypassed altogether for more suitable habitats. It may be instructive that today, with high populations and an agricultural base, only 6000 of Indonesia's 17,000 islands are inhabited. When multiple hunter-gatherer groups are operating entirely within island environments, some islands will have much greater natural suitability than others, whether this is a product of island size, reef size, resource diversity and productivity, availability of water, or combinations of all these things. Water sources, or equivalents such as coconuts, perhaps a less crucial variable on the Sunda mainland, will likely become a more critical one on islands with restricted catchments, making some islands or groups of islands preferred habitats and others very peripheral.

One implication of this is that the next-most-suitable habitat need not be adjacent to the first. Not all islands will be occupied in longitudinal turn and some may be never occupied nor even utilised. As such, our model is neither strictly a diffusionist wave-of-advance model, nor a streaming linear point-and-arrow model (Rockman 2003). While our interest is in a general east-to-west advance, specific islands may have been initially colonised from any direstion.

Thus our model leads us to conclude that the earliest Wallacean colonists selected the most suitable habitats, and when fission occurred, similarly suitable habitats were occupied, even at a distance. We refer to this model as the 'sweet-spot' model, a term coined by Robert Elston (e.g. Elston 1992) to mean a place in a landscape that, given particular hunter-gather technology, diet and population, is optimally located with regard to procuring a suite of resources, including food, water, fuel and shelter. While moving from sweet spot to sweet spot may well have been also the prevailing mode that propelled modern behavioural humans to the edge of Sunda, we believe the nature of the island world of Wallacea refined and intensified it as a strategy for colonising it. Eventually, Sahul loomed on the horizon.

\section{The magic number}

The demographic parameters of successfully colonising Wallacia and Sahul appear to be the missing pages of most such histories. Exceptions include Birdsell's (1957) early modelling that indicated a founding group expanding at ethnographically observed rates might fill Australia to carrying capacity in only several thousand years. Jones (1989:753-756) favoured chance castaway landings that were occasionally successful in establishing viable small populations, but he recognised no account had been taken of the genetic shortcomings of such models. 
Frequently quoted, but least likely, is Calaby's (1976:23-24) imaginative but biologically improbable suggestion that a single pregnant female caught in a flood and swept to sea on a fallen tree or raft of vegetation could have been the Aboriginal Eve.

The general absence of the demographic parameter in the settlement of Sahul is understandable, given that the scales at which archaeology or genetics operate are unlikely to directly inform the problem. As with voyaging simulations in the Indo-Pacific region, demographic simulations of small colonising populations appear to offer the best illumination at present.

An early important attempt in Australia at simulating small founding populations was made by McArthur (1976). McArthur recognised that unlike modelling large populations, the demographic fate of each individual in a small group is of great significance to the fate of the group, but that by assessing the fate of each individual year by year, and introducing birth and marriage (monogamous vs polygamous) and incest rules, the capacity of the 1976 CSIRO computer was rapidly strained. Thus, these simulations ended when any population included either 500 men and women who had ever lived, and/or the maximum timespan for any of the populations generated was 500 years. The simulations were run for groups of three, five and seven couples and whatever the size of the group, groups with younger members had significantly lower probabilities of extinction than those with older couples, but the smaller groups had higher likelihoods of extinction.

McArthur found the slowing down or reversal of a group's demographic increase was traceable to distortions in the sex ratios, either the predominance of one sex among the births, or the failure of some to survive and reproduce. However, under the constraints of the experiment, McArthur was unable to indicate what demographic threshold needed to be achieved for longterm viability.

The problem has recently been re-examined by Moore (2001), who notes that in bands of 25-50 individuals, people are frequently organised around co-resident lineages that restrict potential spouses from marrying opposites who are closely related. In ethnographically described small-scale foraging societies, such marriage restrictions are almost universal. Thus, in small groups, eligible spouses rapidly become rare. Four demographic factors - birth rates, death rates, sex ratio and distribution of sibship size - appear to determine the success of an isolated colonising band. The stochastic nature of birth and death rates can devastate small groups, as can an unbalanced sex ratio, even if women outnumber men and polygyny is adopted, since, other things being equal, the average completed fertility in polygynous marriages is often lower than in monogamous ones. Even if economically viable, such a band will almost inevitably die out unless members either commit incest, a solution with its own fitness costs, or recruit suitable spouses from outside the group.

Again using computer simulations, Moore (2001:400) proposed that unbalanced sex ratios might be more damaging for the long-term viability of a group than fertility issues, especially if long runs of male offspring occur. More telling is the clear indication that lower starting population sizes produce more variable and less predictable results than larger starting populations. Whereas the fate of small groups might turn on a few specific births or deaths, these small events are buffered in larger groups.

Most telling in Moore's simulations is that while the longevity of the group increases with size, no groups of any of the tested sizes up to 60 people avoid extinction, and only rarely do they remain extant for 1000 years in isolation. Such an incursion into Sahul might well remain archaeologically invisible. However, the potential for viability increases significantly if the group exchanges spouses with one other group of equal size. This suggests that if we model the crossing of Wallacea in a 'string-of-pearls' formation, the lead group in the string is as biologically viable 
in its reproductive ability as a group further towards the centre of the string, provided contact with the second group is maintained.

Stemming directly from Moore's analysis (see also Wobst 1974:170-173) is the conclusion that there is no magic number that will assure viability for any isolated small group of huntergatherer colonists crossing Wallacea or entering an empty landscape. While, equally, every small group has some minimal chance of survival, if it arrived as a biologically unbalanced group of castaways on Sahul, its ultimate biological success would seem to be miniscule and dependent on soon being overtaken by subsequent castaway colonists to add to the gene pool. Such an event is probably rare, and even if it did occur, success would require some minimum complementarity in age and gender, as Crusoe realised when he met Friday. The alternate strategy whereby deliberate contact is maintained to bolster potential long-term reproductive success seems to us more probable.

The discussion here has centred on the biological requirements for small pioneering groups entering empty landscapes. We have considered only what Moore refers to as the period of stochastic crisis when extinction might result from the magnified effects of only one or two deaths in a small group. However, if the small group can attain a size at which these critical stochastic events are buffered by the co-occurrence of benevolent events, it may reach the point of 'Malthusian takeoff, when the group begins to increase its population geometrically. At this point, while the threat of extinction recedes, it is replaced by the opposite problem of too many people for the mode of production. While less suitable habitats previously bypassed may now be filled in, or economic intensification might increase the productivity of a habitat, other social solutions, such as infanticide, might also be introduced.

\section{The Timor route}

None of the variables discussed here offers much support for the Timor to the Kimberley coast route. While the target was wide, it was a blind crossing and its value could not be determined by scouting, its location only surmised on the basis of smoke, migrating birds and bushfire glow. It required sufficient technology to cover a longer journey at times of higher sea level, the opportune times to utilise coasts and islands, but from a starting point that may have lacked bamboo, the favoured watercraft-building material. If people could not return to Timor, no new information about what lay ahead was available to subsequent intending colonists. The nature of the Kimberley coast at various lower sea levels is uncertain, but extensive mud flats and lack of fresh water may have been a problem. Lastly, the long-term reproductive viability of colonists taking this route would seem to have depended on being overtaken by subsequent gender- and age-compatible colonists.

Alternatively, these deficiencies appear not to attend the northern route that eventually brought people on to or near the Bird's Head of western New Guinea. This is the most likely route of entry into Sahul.

\section{Conclusion}

We intend to pursue the corollary to this paper, the dispersal of people through Sahul, in another place. However, we note that if people did enter through the Bird's Head, as we suggest, then dispersal eastwards was controlled in large part by geography. The central cordillera running the length of New Guinea, and in places reaching $4000 \mathrm{~m}$ above sea level, is thought to have been shrouded in cloud and inhospitable. This mountain chain formed an effective wedge, isolating people moving along the northern coast towards the Bismarck Archipelago from those moving southwards into Australia. On either side, the catchment of the cordillera provided numerous 
rivers, the basis for coastal and lowland sweet spots. But to the north, the coastline channelled people in string-of-pearls fashion towards the immediate dead-end of the Bismarcks, while to the south, a different scenario was played out.

Despite decades of biological research in Australia and New Guinea that has emphasised the differences between the two regions, recent genetic research has begun to change this situation. There are now three or four shared haplogroups, P3, S, Q2, and possibly P4, that indicate ancient mtDNA linkages (Friedlaender et al. 2005; Friedlaender et al. 2007; Hudjashov et al. 2007). Interestingly, one of these, Group S, is in Papua on the Oriomo Plateau (Figure 1), and thus is south of the cordillera, supporting the view of an early incursion along the southern New Guinea coast towards what is now Australia. The others are from the Bismarck Archipelago. This genetic evidence is more fully considered in O'Connell et al. (2007).

In keeping with our understanding of the ability of behaviourally modern humans to solve problems with technology and determine the costs and benefits of their actions and decisions, we see little to recommend the parsimony of minimalist views that wash the first Australians and New Guineans ashore as helpless castaways. We find equally unpersuasive views that invoke long-distance migration and voyages of exploration in the style of Magellan and Cook. People crossed Wallacea as a consequence of specialised foraging behaviour, in much the same manner as they had travelled from Africa to the edge of Sunda.

\section{References}

Allen, J. and J.F. O'Connell 2003. The long and the short of it: archaeological approaches to determining when humans first colonized Australia and New Guinea. Australian Archaeology 57:5-19.

Anderson, A. 2000. Slow boats from China: issues in the prehistory of Indo-Pacific seafaring. In S. O'Connor and P. Veth (eds), East of Wallace's Line. Studies of Past and Present Maritime Cultures of the Indo-Pacific Region, pp. 13-50. Published as Modern Quaternary Research in South East Asia 16. Rotterdam: Balkema.

Baulig, H. 1935. The Changing Sea Level. The Institute of British Geographers, Publication No. 3. London: George Philip and Son.

Beaton, J.B. 1991. Colonizing continents: some problems from Australia and the Americas. In T.D. Dillehay, and D.J. Meltzer (eds), The First Americans: Search and Research, pp. 209-230. Baton Rouge: CRC Press.

Bellwood, P. 1990. From Late Pleistocene to Early Holocene in Sunderland. In C. Gamble and O. Soffer (eds), The World at 18,000 BP. Vol. 2. Low Latitudes, pp. 255-263. London: Unwin Hyman.

Bird, D.W. and J.F. O'Connell 2006. Behavioral ecology and archaeology. Journal of Archaeological Research 14:143-188.

Birdsell, J.B. 1957. Some population problems involving Pleistocene man. Cold Springs Harbor Symposia on Quantitative Biology 22:47-69.

Birdsell, J.B. 1977. The recalibration of a paradigm for the first peopling of Greater Australia. In J. Allen, J. Golson and R. Jones (eds), Sunda and Sahul. Prehistoric Studies in Southeast Asia, Melanesia and Australia, pp.113-67. London: Academic Press.

Bowdler, S. 1977. The coastal colonisation of Australia. In J. Allen, J. Golson and R. Jones (eds), Sunda and Sahul. Prehistoric Studies in Southeast Asia, Melanesia and Australia, pp.205-245. London: Academic Press.

Bulbeck, D. 2007. Where river meets sea: a parsimonious model for Homo sapiens colonization of the Indian Ocean Rim and Sahul. Current Anthropology 48:315-321. 
Butlin, N.G. 1993. Economics and the Dreamtime. A Hypothetical History. Cambridge: Cambridge University Press.

Calaby, J.H. 1976. Some biogeographical factors relevant to the Pleistocene movement of man in Australasia. In R.L. Kirk and A.G. Thorne (eds), The Origin of Australians, pp. 23-28. Human Biology Series No. 6, Canberra: Australian Institute of Aboriginal Studies.

Chappell, J. 1993. Late Pleistocene coasts and human migrations in the Austral region. In M. Spriggs, D.E. Yen, W. Ambrose, R. Jones, A. Thorne and A. Andrews (eds), A Community of Culture. The People and Prehistory of the Pacific, pp. 43-48. Occasional Papers in Prehistory, No. 21. Canberra: Department of Prehistory, Research School of Pacific Studies, The Australian National University.

Chappell, J. 2000. Pleistocene seedbeds of western Pacific maritime cultures and the importance of chronology. In S. O'Connor and P. Veth (eds), East of Wallace's Line. Studies of Past and Present Maritime Cultures of the Indo-Pacific Region, pp. 77-98. Published as Modern Quaternary Research in South East Asia 16. Rotterdam: Balkema.

Chappell, J., J. Head and J. Magee 1996. Beyond the radiocarbon limit in Australian archaeology and Quaternary research Antiquity 70:543-552.

Daly, R.A. 1910. Pleistocene glaciation and the coral reef problem. American Journal of Science (4th series) 30:297-308.

Dunn, F.L. and D.F. Dunn 1977. Maritime adaptations and the exploration of marine resources in Sundaic Southeast Asian prehistory. Modern Quaternary Research in Southeast Asia 3:1-28.

Elkin, A.P. 1978. N.W.G. Macintosh and his work. Archaeology and Physical Anthropology in Oceania $13(2 \& 3): 85-142$.

Elston, R.G. 1992. Economics and strategies of lithic procurement at Tosawihi. In R.G. Elston and C. Raven (eds), Archaeological Investigations at Tosawihi, a Great Basin Quarry. Part 1: The Periphery, pp. 775-802. Report to Ivanhoe Gold Company, Winnemucca, Nevada by Intermountain Research, Silver City, Nevada.

Fifield, L.K., M.I. Bird, C.S.M. Turney, P.A. Hausladen, G.M. Santos and M.L. di Tada 2001. Radiocarbon dating of the human occupation of Australia prior to $40 \mathrm{ka} \mathrm{BP}$ - successes and pitfalls. Radiocarbon 43:1139-1145.

Foley R. and M.M. Lahr 1997. Mode 3 technologies and the evolution of modern humans. Cambridge Archaeological Journal 7(1):3-36.

Fretwell, S.D. 1972. Populations in a Seasonal Environment. Princeton: Princeton University Press.

Friedlaender, J.S., T.G. Schurr, F. Gentz, G. Koki, F.R. Friedlaender, G. Horvat, P. Babb, S. Cerchio, F. Kaestle, M. Schanfield, R. Deka, R. Yanagihara and D.A. Merriwether 2005. Expanding Southwest Pacific Mitochondrial Haplogroups P and Q. Molecular Biology and Evolution 22:1506-1517.

Friedlaender, J. S., F.R. Friedlaender, J.A. Hodgson, M. Stoltz, G. Koki, G. Horvat, S. Zhadonov, T.G. Schurr, and D.A. Merriwether 2007. Melanesian mtDNA Complexity. PLoS ONE 2(2): e248.doi:10.1371/journal.pone.0000248.

Hiatt, L.R. 2001. Homo Mobilis. In A. Anderson, I. Lilley and S. O'Connor (eds), Histories of Old Ages. Essays in honour of Rhys Jones, pp. 111-21. Canberra: Pandanus Books.

Horton, D.R. 1981. Water and woodland; the peopling of Australia. Australian Institute of Aboriginal Studies Newsletter 16:21-27.

Hudjashov, G., T. Kivisild, P.A. Underhill, P. Endicott, J.J. Sanchez, A.A. Lind, P. Shen, P. Oefner, C. Renfrew, R. Villems and P. Forster 2007. Revealing the prehistoric settlement of Australia by Ychromosome and mtDNA analysis. Proceedings of the National Academy of Science 104(21): 8726-8730.

Irwin, G. 1992. The Prehistoric Exploration and Colonisation of the Pacific. Cambridge: Cambridge University Press.

Jones, R. 1989. East of Wallace's Line: issues and problems in the colonisation of the Australian continent. In P. Mellars and C. Stringer (eds), The Human Revolution. Behavioural and Biological 
Perspectives on the Origins of Modern Humans, pp. 743-782. Edinburgh: Edinburgh University Press.

Kirch, P.V. 2002. On The Road of the Winds: An Archaeological History of the Pacific Islands before European Contact. Berkeley: University of California Press.

Lambeck, K. and J. Chappell 2001. Sea level change through the last glacial cycle. Science 292:679-686.

Lima, S.L. and P.A. Zollner 1996. Towards a behavioural ecology of ecological landscapes. Trends in Ecology and Evolution 11:131-135.

McArthur, N. 1976. Computer simulations of small populations. Australian Archaeology 4:53-57.

Moore, J.H. 2001 Evaluating five models of colonization. American Anthropologist 103:395-408.

Mulvaney, J. and J. Kamminga 1999. Prehistory of Australia. St. Leonards, Sydney: Allen and Unwin.

Munro, W. 1868. A Monograph of the Bambusaceae Including Description of All the Species. London: The Linnean Society.

O'Connell, J.F. and J. Allen 2004. Dating the colonization of Sahul (Pleistocene Australia-New Guinea): a review of recent research. Journal of Archaeological Science 31:835-853.

O'Connell, J.F. and J. Allen 2007. Pre-LGM Sahul (Australia-New Guinea) and the archaeology of early modern humans In P. Mellars, K. Boyle, O. Bar-Yosef and C. Stringer (eds), Rethinking the Human Revolution, pp. 395-410. Cambridge: McDonald Institute for Archaeological Research.

O'Connell, J.F., J. Allen and K. Hawkes 2007. Modeling Sahul colonization: implications for the origins of seafaring. Paper presented at the workshop 'Origins of Seafaring.' MacDonald Institute, Cambridge University. August 2007.

O'Connor, S. 2007. Pleistocene Migration and Colonisation in the Indo-Pacific Region. Paper presented at the workshop 'Origins of Seafaring.' MacDonald Institute, Cambridge University. August 2007.

O'Connor, S. and J. Chappell 2003. Colonisation and coastal subsistence in Australia and Papua New Guinea: different timing, different modes? In C. Sand (ed), Pacific Archaeology: assessments and prospects, pp. 17-32. Le Cahiers de l'Archéologie en Nouvelle-Calédonie 15. Nouméa: Departement Archéologie, Service des Musées et du Patrimoine de Nouvelle-Calédonie.

Roberts, R.G., R. Jones and M.A. Smith 1990. Thermoluminescence dating of a 50,000 year old human occupation site in northern Australia. Nature 345:153-156.

Rindos, D. and E. Webb 1992. Modelling the initial colonisation of Australia: perfect adaptation, cultural variability and cultural change. Proceedings of the Australasian Society for Human Biology 5:441-454.

Rockman, M. 2003. Knowledge and learning in the archaeology of colonization. In M. Rockman and J. Steele (eds), Colonization of Unfamiliar Landscapes: The Archaeology of Adaptation, pp. 3-24. London: Routledge.

Stephens, D.W. and J.R. Krebs 1986. Foraging Theory. Princeton: Princeton University Press.

Thiel, B. 1987. Early settlement of the Philippines, Eastern Indonesia, and Australia-New Guinea: a new hypothesis. Current Anthropology 28(2):236-241.

Torgersen, T., J. Luly, P. De Deckker, M.R. Jones, D.E. Searle, A.R. Chivas and W.J. Ullman 1988. Late quaternary environments of the Carpentaria Basin, Australia. Palaeogeography, Palaeoclimatology, Palaeoecology 67(3-4): 245-261.

Voris, H.K. 2000. Maps of Pleistocene sea levels in Southeast Asia: Shorelines, river systems and time durations. Journal of Biogeography 27:1153-1167.

Wild, S. 1985. Voyaging to Australia: 30,000 years ago. Proceedings of Ausgraph 85. Brisbane: Third Australasian Conference on Computer Graphics.

Wobst, H.M. 1974. Boundary conditions for Palaeolithic social systems: a simulation approach. American Antiquity 39:147-178. 